\title{
Forgetting in recognition memory with and without recollective experience
}

\author{
JOHN M. GARDINER and ROSALIND I. JAVA \\ City University, London, England
}

\begin{abstract}
Retention interval was manipulated in two recognition-memory experiments in which subjects indicated when recognizing a word whether its recognition was accompanied by some recollective experience ("remember") or whether it was recognized on the basis of familiarity without any recollective experience ("know"). Experiment 1 showed that between 10 min and 1 week, "remember" responses declined sharply from an initially higher level, whereas "know" responses remained relatively unchanged. Experiment 2 showed that between 1 week and 6 months, both kinds of responses declined at a similar, gradual rate and that despite quite low levels of performance after 6 months, both kinds of responses still gave rise to accurate discrimination between target words and lures. These findings are discussed in relationship to current ideas about multiple memory systems and processing accounts of explicit and implicit measures of retention.
\end{abstract}

Memory links time present with time past. In recognition memory, the phenomenal experience of the link between the present and the past can take at least two distinct forms. Recognition can be accompanied by either conscious recollection of some specific experience or feelings of familiarity without any recollective experience. Recognition memory with and without recollective experience can be measured by "remember" and "know" responses (Tulving, 1985b). A "remember" response indicates that seeing the word in the test list brings back to mind some specific recollection of what was experienced when the word appeared in the study list. A "know" response indicates that seeing the word in the test list brings to mind feelings of familiarity, without any recollective experience.

Recent studies have shown that these measures of recognition with and without recollective experience produce principled outcomes. Quite a few independent variables have been found to influence "remember" responses but not "know" responses. These variables include levels of processing and generate-versus-read study conditions (Gardiner, 1988a), word frequency (Gardiner \& Java, 1990), divided-versus-undivided attention (Gardiner \& Parkin, 1990), intentional-versus-incidental learning and number of rehearsals (Macken \& Hampson, 1991), presentation mode (Gregg \& Gardiner, 1991), and threateningversus-nonthreatening words (Mogg, Gardiner, Stavrou, \& Golombok, in press).

But some variables have also been found to influence "know" responses. Compared with words, nonwords gave rise to more "know" responses and fewer "remember" responses (Gardiner \& Java, 1990). Compared with

Correspondence about this article should be addressed to John Gardiner, Memory \& Cognition Research Group, Department of Social Sciences, City University, Northampton Square, London ECIV OHB, England. young adults, elderly adults produced more "know" responses and fewer "remember" responses (Parkin \& Walter, 1991). And Blaxton (1991) found a similar pattem of results after comparing data-driven with conceptually driven processing tasks at study and also after comparisons of epileptic patients who had left-temporal-lobe lesions with epileptic patients who had right-temporal-lobe lesions.

In many cases, these results bear a striking resemblance to the results found in comparisons between performance in explicit and implicit memory tests (for reviews, see Richardson-Klavehn \& Bjork, 1988; Schacter, 1987). For example, levels of processing have been found to influence performance in explicit but not implicit tests (Graf \& Mandler, 1984; Jacoby \& Dallas, 1981); similar results have been found for generate-versus-read study conditions (Gardiner, 1988b), for divided-versus-undivided attention (Parkin, Reid, \& Russo, 1990), and for intentional-versusincidental learning and number of rehearsals (Greene, 1986).

The theories most directly implicated by "remember" and "know" measures are Tulving's (1983, 1985a, 1985b) distinction between episodic memory and other memory systems and Mandler's $(1980,1988)$ distinction between the elaboration and the activation or integration of information. In Tulving's theory, a "remember" response reflects episodic memory, because recollective experience (or autonoetic consciousness) is a defining characteristic of that system. A "know" response (or noetic consciousness) is characteristic of semantic memory, because knowledge retrieved from semantic memory is not normally accompanied by recollective experience. In Mandler's theory, a "know" response is characteristic of the activation or integration of information, because it is activation or integration that gives rise to feelings of familiarity; recollective experience is based on elaboration.

It has also been suggested (Gardiner, 1988a; Gardiner \& Java, 1990; Gardiner \& Parkin, 1990) that "remem- 
ber" and "know" responses can be interpreted within a theoretical framework that combines Tulving's (1983, $1985 \mathrm{a}, 1985 \mathrm{~b}$ ) theory with the transfer-appropriate processing account of differences between explicit and implicit measures of retention (Roediger \& Blaxton, 1987; Roediger, Weldon, \& Challis, 1989). This suggestion accords with a theoretical rapprochement recently discussed by Hayman and Tulving (1989), Schacter (in press), and Tulving and Schacter (1990; see also Richardson-Klavehn \& Bjork, 1988; Roediger et al., 1989). By this account, "remember" responses depend on conceptual processing in episodic memory, and "know" responses reflect data-driven processing, or "perceptual fluency" (Jacoby, 1983; Jacoby \& Dallas, 1981), perhaps arising from the perceptual representation systems Tulving and Schacter (1990; see also Schacter, in press) have recently discussed in relation to priming.

This suggestion is consistent with the results of the study by Blaxton (1991) which was on recognition memory for abstract visuospatial designs. Blaxton showed that memoryunimpaired adults made more "remember" than "know" responses following a conceptually driven study task and more "know" than "remember" responses following a data-driven study task. Moreover, she showed that regardless of study task, epileptic patients with left-temporallobe lesions and impaired verbal memory made more "know" than "remember" responses, and epileptic patients with right-temporal-lobe lesions and impaired visuospatial memory made more "remember" than "know" responses.

Dissociations of the kind found by Blaxton (1991) are difficult to reconcile with another theoretical possibility, which is that "know" responses might merely reflect weak trace strength. There is other evidence against this possibility in the studies by Gardiner and Java (1990) and Parkin and Walter (1991). Gardiner and Java not only found more "know" than "remember" responses for nonwords, compared with more "remember" than "know" responses for words, but also that the higher level of "know" responses for nonwords corresponded with high confidence ratings. In a post hoc analysis, Parkin and Walter showed that their finding of more "know" and fewer "remember" responses in elderly adults compared with young adults held good even when the overall levels of performance in the two age groups were equated.

The present research was expected to further clarify these theoretical issues, especially concerning the interpretation of "know" responses, but the research had a straightforward empirical goal-the need for further evidence about the forgetting characteristics of recognition memory as measured by "remember" and "know" responses. In each case, the aim was to obtain good evidence about the persistence of recognition memory and about the rate of forgetting.

In one previous study with "remember" and "know" measures that manipulated retention interval (Gardiner, 1988a, Experiment 2), there were two retention intervals of $1 \mathrm{~h}$ and 1 week. The proportion of correct "remem- ber" responses declined sharply after a week, but the proportion of correct "know" responses changed little. However, the proportion of "know" responses to lure words rose sharply after a week and was not reliably lower than the proportion of correct "know' responses. The longest retention interval over which there is evidence of accurate discrimination with "know" responses is $24 \mathrm{~h}$, a retention interval used by Gardiner and Java (1990) to avoid ceiling effects. Thus, it is possible that accurate "know" responses may not persist for much longer than a 24-h period.

So far as forgetting rate is concerned, the general finding since the classic study by Ebbinghaus (1885/1964), both in laboratory studies (e.g., Wickelgren, 1972) and in autobiographical memory (e.g., Rubin, 1982), is that forgetting occurs rapidly at first and then slows downalthough in very long-term memory, there is some conflicting evidence about whether there is any forgetting at all (Bahrick, 1984; Bahrick, Bahrick, \& Wittlinger, 1975; Squire, 1989). The rate of forgetting is remarkably immune to the effects of most independent variables (Underwood, 1964, 1969). It is important to note that, as Slamecka and McElree (1983) have more recently confirmed, these variables include original degree of learning and item difficulty (see Baddeley, 1990, for a brief review).

We describe two similar experiments, in each of which a different group of subjects was assigned to each different retention interval. In Experiment 1, the retention intervals were $10 \mathrm{~min}, 1 \mathrm{~h}, 1$ day, and 1 week.

\section{EXPERIMENT 1}

\section{Method}

Subjects. The subjects were 64 undergraduate students at City University, London, who were paid for their participation in the experiment. They were allocated arbitrarily to one of four separate groups of 16 subjects. All subjects were tested individually. Three subjects, all in the 10-min group, evidently failed to comprehend or act upon the instructions. These subjects were replaced.

Design and Materials. The experiment involved a single-factor independent groups design, with retention interval as the factor. The four retention intervals were $10 \mathrm{~min}, 1 \mathrm{~h}, 1$ day, and 1 week. Subjects were allocated to each group partly by order of arrival at the laboratory, partly by availability for testing.

The stimulus materials were a set of 72 words selected randomly from the materials used by Tulving, Schacter, and Stark (1982), subject to the exclusion of a few words likely to have been unknown to some of the subjects. The recognition test lists consisted of all 72 words. There were four different study lists, derived from two random divisions of all 72 words into equal subsets of 36 words. The four different study lists resulted from counterbalancing target words and lures within each such division. Within each group, each study list was used equally often.

At study, the subjects were told simply to memorize the words for a subsequent test, the nature of which was not specified at the time. At test, the subjects were required to give "remember" or "know" judgments for each word they recognized.

Procedure. The study-list words were printed on a deck of cards and presented at the rate of $2 \mathrm{sec} /$ word, in an order randomized separately for every subject. The subjects were told to memorize the words for a subsequent memory test, about which they were given no further information until the test began. The subjects al- 
located to the 10 -min retention interval were during that time engaged in winsome conversation with the experimenter. The subjects allocated to the other retention intervals were dismissed and told to return to the laboratory at the time designated for the test but, in the meantime, not to think about the words.

For the recognition test, all 72 words were printed, in a single constant order, in three columns of 24 words each. The subjects were instructed to work down each column carefully in turn, drawing a circle around any word that they recognized from the study list. In addition, they were told to put an " $R$," for "remember," or $\mathrm{a}$ " $\mathrm{K}$," for "know," alongside each word they recognized. As in previous similar studies (e.g., Gardiner \& Parkin, 1990), the subjects were given a typewritten set of instructions describing these two kinds of responses, supplemented by oral instructions for further clarification as necessary. A "remember" response was described as some specific recollection of what was experienced the moment the word appeared in the study list. Examples included an association with another list word, an image that came to mind, something about the physical appearance or position of the word, or something of personal significance in autobiographical memory. A "know" response was described as recognition that is without any such item-specific recollective experience but that is accomplished on some other basis, particularly feelings of familiarity (see Gardiner \& Java, 1990, and Gardiner \& Parkin, 1990, for a more detailed account of the instructions).

The recognition test was self-paced, though backtracking was discouraged and the subjects were also discouraged from guessing.

\section{Results and Discussion}

The principal results from this experiment are summarized in Table 1, which shows the mean proportion of "remember" and "know" responses to target words and lures at each retention interval. The table shows that whereas the mean proportion of correct "remember" responses declined sharply over retention interval, there was little change in the mean proportion of correct "know" responses. False-positive rates were quite low and tended to increase slightly at the longer retention intervals.

Previous studies using "remember" and "know" measures have tended to report one or the other of two alternative ways in which the data may be analyzed. In one, the analysis of variance (ANOVA) includes response type as a factor on the questionable grounds that it can be regarded as an instructional manipulation. In the other, a separate ANOVA is carried out on "remember" and on "know" responses. The latter approach precludes the evaluation of interactions involving response type but is less questionable statistically. For the experiments described here, we report the results from both kinds of anal-

Table 1

Response Probability as a Function of Retention Interval in Experiment 1

\begin{tabular}{lcccc}
\hline \multirow{2}{*}{$\begin{array}{c}\text { Retention } \\
\text { Interval }\end{array}$} & \multicolumn{2}{c}{ Target Words } & \multicolumn{2}{c}{ Lures } \\
\cline { 2 - 3 } \cline { 5 - 5 } "Remember" "Know" & "Remember" & "Know" \\
\hline 10 min & .49 & .26 & .00 & .05 \\
1 h & .42 & .24 & .01 & .06 \\
1 day & .27 & .27 & .03 & .06 \\
1 week & .25 & .23 & .05 & .08 \\
\hline
\end{tabular}

yses. We also report the results of separate analyses of individual subject hit rates and of individual subject scores corrected by subtracting each person's false-alarm rate from the corresponding hit rate. The alpha level was set at .05 throughout.

The results of an ANOVA with response type as a factor on uncorrected scores showed that the main effects of retention interval $\left[F(3,60)=10.82, M S_{\mathrm{e}}=12.83\right]$ and of response type $\left[F(1,60)=15.45, M S_{e}=34.72\right]$ were both reliable. The interaction between retention interval and response type was significant $\left[F(3,60)=4.39, M S_{\mathrm{e}}\right.$ $=34.72$ ]. The results of a similar ANOVA on corrected scores also showed significant main effects of retention interval $\left[F(3,60)=12.70, M S_{\mathrm{c}}=15.87\right]$ and of response type $\left[F(1,60)=27.35, M S_{\mathrm{e}}=27.98\right]$. Their interaction was also significant $\left[F(3,60)=5.10, M S_{\mathrm{e}}=27.98\right] .{ }^{1}$

Separate ANOVAs on uncorrected "remember" and "know" scores revealed a significant effect for "remember" responses $\left[F(3,60)=9.47, M S_{\mathrm{e}}=30.28\right]$ but not for "know" responses $(F<1)$. For the corrected scores, there was again a significant effect for "remember" responses $\left[F(3,60)=12.46, M S_{\mathrm{e}}=26.46\right]$ but not for "know" responses $(F<1)$.

No ANOVA was carried out on individual subject responses to lures because too few responses were made. It is clear, however, that "know" responses to lures exceeded "remember" responses to lures, as has been found in previous similar studies (e.g., Gardiner \& Java, 1990), and that both kinds of lure responses increased with longer retention intervals. At each retention interval, for each kind of response, the hit rate significantly exceeded the false-alarm rate by sign test.

Although it is well established that the rate of forgetting does not depend either on the degree of original learning or on whether retention is measured for easy or difficult items (Baddeley, Baddeley, \& Nimmo-Smith, cited in Baddeley, 1990; Slamecka \& McElree, 1983; Underwood, 1964), it is nonetheless possible that the initial differences that were observed in forgetting rates for "remember" and "know" measures over the first three retention intervals might reflect scaling problems associated with differences in the initial levels of performance. This possibility can be checked by examining the data at each of these three retention intervals for the 8 subjects whose hit rates for "know" responses were above the median (see Gardiner \& Parkin, 1990). These 8 subjects had average hit rates across the three retention intervals of $.36, .34$, and .35 . In contrast, the average "remember" hit rates for the 8 subjects whose hit rates fell below the median were $.19, .14$, and .09 . These data provide no evidence that scaling problems underlie the absence of any sharp drop in "know" responses over the earlier retention intervals.

The main conclusions from Experiment 1 are that recognition memory without recollective experience persists for at least as long as 1 week (cf. Gardiner, 1988a) and, 
during this period, shows relatively little evidence of forgetting. In contrast, over the same period, recognition memory with recollective experience declines sharply.

\section{EXPERIMENT 2}

Experiment 2 had two main aims: first, to replicate the finding that recognition memory measured by "know" responses persists for at least 1 week and, second, to extend "remember" and "know" measures of recognition memory to much longer retention intervals. Accordingly, in Experiment 2, there were three retention intervals: 1 week, 4 weeks, and 6 months.

\section{Method \\ Subjects. The subjects were another group of 48 undergraduate students at City University, London, who were paid for their par- ticipation in the experiment. They were allocated arbitrarily to one of three separate groups of 16 subjects. All subjects were tested individually. One subject, in the 4-week group, was replaced for failing to carry out the instructions properly. \\ Design, Materials, and Procedure. The design, materials, and procedure were essentially the same as in Experiment 1, except that the retention intervals were 1 week, 4 weeks, and 6 months.}

\section{Results and Discussion}

The principal results from this experiment are summarized in Table 2, which shows the mean proportion of "remember" and "know" responses to target words and lures at each retention interval. In contrast to the results of Experiment 1, the results here show a broadly similar pattern for "remember" and "know" responses to target words, both of which declined gradually as the retention intervals increased. At the 1-week retention interval, the results from this experiment correspond quite closely with those from Experiment 1. And although performance generally declined to quite low levels by 6 months, both "remember" and "know" responses to target words exceeded those made to lures.

The results of an ANOVA that had response type as a factor and that was carried out on uncorrected hit rates showed that there was a significant main effect of retention interval $\left[F(2,45)=12.05, M S_{\mathrm{e}}=6.36\right]$ but that neither the main effect of response type nor the interaction between retention interval and response type was significant $(F<1$, in each case). The results of a similar ANOVA on corrected scores also showed a significant main effect of retention interval $\left[F(2,45)=10.72, M S_{\mathrm{e}}=5.71\right]$; neither the main effect of response type $[F(1,45)=2.75$, $\left.M S_{e}=19.10\right]$ nor the interaction $(F<1)$ was significant.

Table 2

Response Probability as a Function of Retention Interval in Experiment 2

\begin{tabular}{lccccc}
\hline \multirow{2}{*}{$\begin{array}{c}\text { Retention } \\
\text { Interval }\end{array}$} & \multicolumn{2}{c}{ Target Words } & \multicolumn{2}{c}{ Lures } \\
\cline { 2 - 3 } \cline { 5 - 6 } 1 week & .24 & .25 & .05 & .10 \\
4 weeks & .19 & .21 & & .02 & .09 \\
6 months & .15 & .17 & .05 & .09 \\
\hline
\end{tabular}

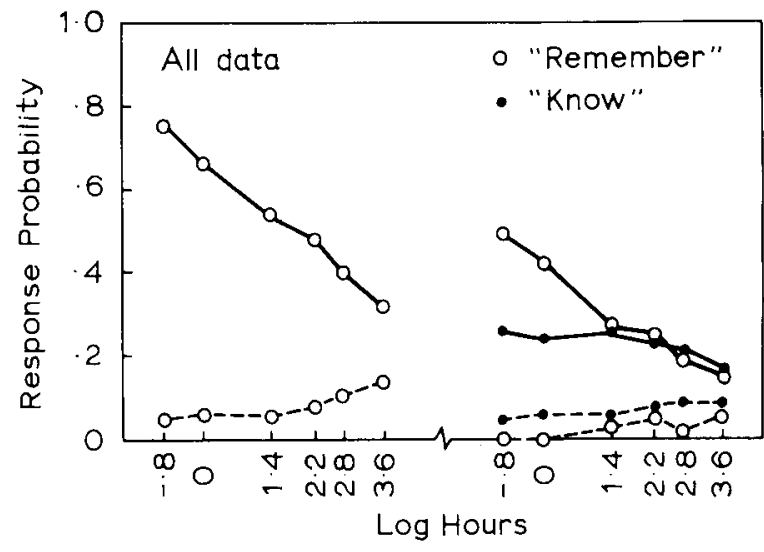

Figure 1. Response probability as a function of $\log$ hours.

Separate ANOVAs on uncorrected "remember" and "know" scores revealed a significant effect both for "remember" responses $\left[F(2,45)=4.73, M S_{\mathrm{e}}=8.72\right]$ and for "know" responses $\left[F(2,45)=4.99, M S_{\mathrm{e}}=\right.$ 7.23]. For the corrected scores, the effect was not quite significant either for "remember" responses $[F(2,45)=$ $\left.2.81, M S_{\mathrm{e}}=13.47\right]$ or for "know" responses $[F(2,45)=$ $\left.2.20, M S_{\mathrm{e}}=11.23\right]$.

As in Experiment 1, the proportion of "know" responses to lure words exceeded the proportion of "remember" responses to lure words, but at these longer retention intervals there was little sign of any tendency for falsepositive rates to systematically increase. No ANOVA was carried out on individual subject responses to lures, again because of the generally low number of responses. At the longer retention intervals, the differences between "know" responses to target words and to lures were quite small, but they were very consistent across subjects. A $t$ test carried out on individual subject "know" responses to targets versus lures at the 6-month interval was highly significant $[t(15)=4.37, S E=.02]$, and so, too, was a similar test at the 4-week interval $[t(15)=5.78, S E=$ $.02]$. For both kinds of responses at all other retention intervals, hit rates significantly exceeded the corresponding false-alarm rates by sign test.

The results of Experiment 2 therefore provide evidence that both recognition memory with recollective experience and recognition memory without recollective experience persist for at least 6 months. They also show that over these longer retention intervals, both forms of recognition memory decline gradually at a similar rate.

For illustrative purposes, the results of Experiments 1 and 2 may be combined to show forgetting curves over the full range of retention intervals tested. To this end, it was arbitrarily decided to include the 1-week data from Experiment 1 and to omit the 1-week data from Experiment 2 . There were, therefore, six sets of data, for retention intervals of $10 \mathrm{~min}, 1 \mathrm{~h}, 1$ day, 1 week, 4 weeks, and 6 months. Figure 1 summarizes these data as a function of log hours, with "remember" and "know" responses combined to give conventional hit-rate and false-alarm- 
rate measures in the left-hand panel and shown separately in the right-hand panel.

The left-hand panel of Figure 1 shows that, considered overall, these data conform with classic forgetting functions which, when plotted logarithmically, usually appear linear. The right-hand panel shows that recognition memory with recollective experience and recognition memory without recollective experience have quite different forgetting rates over shorter retention intervals of up to $24 \mathrm{~h}$.

\section{GENERAL DISCUSSION}

This research had two straightforward empirical goals. The first was to discover the persistence of recognition memory with and without recollective experience, as measured by "remember" and "know" responses. The second was to obtain evidence about forgetting rates with each of these two measures. The results seem relatively clear-cut. Recognition without recollective experience persists for at least 6 months, as does recognition with recollective experience. Also, both forms of recognition memory have different forgetting rates. Recognition accompanied by recollective experience is initially higher but declines sharply over a $24-h$ period. In contrast, recognition without recollective experience shows little forgetting over the first $24 \mathrm{~h}$. Thereafter, both kinds of recognition memory decline gradually, at about the same rate, from $24 \mathrm{~h}$ up to at least 6 months. The difference in forgetting rates provides further evidence against the idea that "remember" and "know" responses correspond with strong and weak memory traces, because it has been established that forgetting rates for strong and weak items do not differ. ${ }^{2}$

Of course, it is possible that over time, "remember" responses become "know" responses as specific contextual information is lost, contrary to the suggestion that the relationship between "remember" and "know" responses is one of exclusivity (see Gardiner \& Parkin, 1990). But we suspect that it would require quite a complicated set of assumptions to fully account for the two forgetting functions in this way. Furthermore, in an additional experiment in which we used a test-retest procedure, we found no evidence that "know" responses in the second of the two tests (which took place a week later) included a relatively high proportion of items to which a "remember" response had been given in the first test. "Know" responses in the second test included only a small proportion of "remember" responses from the first test, and "remember" responses in the second test included a similarly small proportion of "know" responses from the first test. Finally, in thinking about the relationship between "remember" and "know" responses, it should be borne in mind that previous studies have provided good evidence that "remember" and "know" responses reflect qualitatively distinct components of recognition memory, not some unitary quantitative dimension such as trace strength (Blaxton, 1991; Gardiner \& Java, 1990; Parkin \& Walter, 1991).
The elucidation of other possible reasons for the difference in forgetting functions for "remember" and "know" responses will have to await further research. But one likely possibility is that of differential susceptibility to interference. Initially, "remember" responses may be quite vulnerable to interference, whereas "know" responses may be quite resistant to interference. This possibility is consistent with evidence that certain priming effects in implicit memory also seem relatively immune to interference effects (Sloman, Hayman, Ohta, Law, \& Tulving, 1988).

Our findings do not provide much support for the account provided by Mandler's $(1980,1988)$ distinction between elaboration and activation or integration. The persistence of recognition memory as measured by "know" responses for as long as 6 months is not consistent with an interpretation of these responses with respect to temporary activation or integration. There are at least four other pieces of evidence that are difficult to square with this activation view. Gardiner and Java (1990) found that the word-frequency effect in recognition memory, which, together with word-frequency effects in certain priming tasks, has been attributed to enhanced activation (e.g., Jacoby \& Dallas, 1981; Mandler, 1980), did not give rise to more "know" responses. Rather, it gave rise to more "remember" responses. Gardiner and Java also found that the probability of "know" responses was greater for nonwords than for words, a result that cannot easily be explained by the activation of representations in semantic memory. Similarly, Blaxton's (1991) demonstration that "remember" responses were enhanced by conceptually driven processing and that "know" responses were enhanced by data-driven processing involved recognition memory for novel, abstract visuospatial designs. Finally, Mogg et al. (in press) found that although clinically anxious patients show more direct priming of threat than of nonthreat words in word-stem completion, a result that has been explained by enhanced activation of threatening stimuli (Williams, Watts, MacLeod, \& Mathews, 1988), in recognition memory, clinically anxious patients gave no more "know" responses to threat words than did normal controls

Thus Mandler's $(1980,1988)$ distinction between elaboration and activation or integration, and his assumption that activation or integration gives rise both to certain priming effects, such as those observed in word-stem completion, and to feelings of familiarity in recognition memory do not seem to provide a good account of results obtained from "remember" and "know" measures of recognition (cf. Macken \& Hampson, 1991). The problem, for this account, is that recognition measured by "know" responses does not seem to correspond with feelings of familiarity that can be attributed to activation or integration.

Blaxton (1991) argued that "remember" responses reflect conceptual processing and that "know" responses reflect data-driven processing. Although her evidence provides good support for this interpretation, this processing 
account is not necessarily incompatible with a memorysystems account, and there are advantages in a theoretical framework that combines the two approaches (Gardiner, 1988; Gardiner \& Java, 1990; Gardiner \& Parkin, 1990).

Within Tulving's (1983, 1985a, 1985b) distinction between episodic memory and other memory systems, "remember" responses tap autonoetic consciousness and reflect output from the episodic system, and "know" responses tap noetic consciousness, which characterizes the semantic system. However, the evidence that is problematic for an activation account of "know" responses is, by the same token, problematic for a semantic-memory account. That is why Gardiner and Parkin (1990; see also Gardiner, 1988a; Gardiner \& Java, 1990; Mogg et al., in press) suggested that in recognition memory, "know" responses may arise from the perceptual-representation systems that have been proposed to account for certain priming effects in implicit memory (Schacter, in press; Tulving \& Schacter, 1990). Such perceptual systems are presumed to operate at a presemantic level and can, for example, represent structural descriptions either of unfamiliar objects (see Schacter, Delaney, \& Cooper, 1990) or of the visual forms of words but not their meanings. Therefore, this account can readily accommodate evidence that "know" responses in recognition memory are generally not influenced by semantic factors and also occur for unfamiliar stimuli such as nonwords and abstract visuospatial designs.

An additional advantage of this account is that it can readily accommodate long-lasting effects, such as those found in the present experiments and others found with certain priming measures, for example, word-fragment completion (Sloman et al., 1988). A single, brief encounter with a stimulus can lead to fairly durable modification of the perceptual system (cf. Kolers \& Roediger, 1984). Indeed, as Schacter et al. (1990; see also Sherry \& Schacter, 1987) have pointed out, a fairly durable change is to be expected if the encounter is to have any real adaptive significance for the organism.

A systems approach makes good sense from an evolutionary standpoint. In evolutionary terms, recognition must be considered a relatively primitive form of memory. It is therefore not surprising that recognition is quite often accompanied by noetic rather than by autonoetic consciousness. Noetic and autonoetic consciousness must have evolved to meet very different adaptive needs, and one can only speculate about what those needs might be. Reaching a better understanding of the nature and adaptive significance of these two kinds of conscious awareness is one of the more important challenges that we face.

But attempts to explain consciousness with reference to hypothetical mental processes and memory systems do not capture the significance of personal experience from the person's point of view. Such explanations represent what Velmans (in press) called "third-person" accounts, rather than "first-person" accounts. Velmans argued that both third-person and first-person accounts are needed for a complete psychology of memory and that the two kinds of account should be regarded as complementary.

For the subject, the significance of recognition memory accompanied by recollective experience is that the act of recognition has a particular mental cause. A "remember" response involves mental causation in the sense that the subject can make statements such as "I recognize TABLE because I remember that when TABLE occurred in the study list it reminded me that last night at dinner I spilled some wine." A "know" response does not have a specific mental cause. The subject cannot make statements that explain the particular reasons for the act of recognition. Recognition is instead attributed to feelings of familiarity. ${ }^{3}$

From a first-person perspective, then, recognition memory with and without recollective experience corresponds to recognition memory with and without a particular mental cause. Studies in which these two mental states have been measured by "remember" and "know" responses converge on the unavoidable conclusion that recognition that has some specific mental cause and recognition that has no particular mental cause differ in systematic, fundamental ways.

\section{REFERENCES}

BADDELEY, A. D. (1990). Human memory: Theory and practice. Hillsdale, NJ: Erlbaum.

BAHRICK, H. P. (1984). Semantic memory content in permastore: Fifty years of memory for Spanish learned in school. Journal of Experimental Psychology: General, 113, 1-47.

BAhrick, H. P., BAhrick, P. O., \& Wittlinger, R. P. (1975). Fifty years of memories for names and faces: A cross-sectional approach. Journal of Experimental Psychology: General, 104, 54-75.

Blaxton, T. A. (1991). The role of temporal lobes in memory function: Conceptual and data-driven transfer. Manuscript submitted for publication.

Ebbinghaus, E. E. (1964). Memory (H. A. Ruger \& C. E. Bussenius, Trans.). New York: Dover. (Original work published 1885)

GARDINER, J. M. (1988a). Functional aspects of recollective experience. Memory \& Cognition, 16, 309-313.

GARDINER, J. M. (1988b). Generation and priming effects in wordfragment completion. Journal of Experimental Psychology: Learning, Memory, \& Cognition, 14, 495-501.

GARDINER, J. M., \& JAVA, R. I. (1990). Recollective experience in word and nonword recognition. Memory \& Cognition, 18, 23-30.

Gardiner, J. M., PARKIN, A. J. (1990). Attention and recollective experience in recognition memory. Memory \& Cognition, 18, 579-583.

GRAF, P., \& MANDLER, G. (1984). Activation makes words more accessible, but not necessarily more retrievable. Joumal of Verbal Leaming \& Verbal Behavior, 23, 553-568.

GREENE, R. L. (1986). Word stems as cues in recall and completion tasks. Quarterly Journal of Psychology, 38A, 663-673.

GreGG, V. H., GARDINER, J. M. (1991). Components of conscious awareness in a long-term modality effect. British Joumal of Psychology, 82, 153-162.

Hayman, C. A. G., \& Tulving, E. (1989). Is priming a fragment completion based on a "traceless" memory system? Joumal of Experimental Psychology: Leaming, Memory, \& Cognition, 15, 941-956.

JACOBY, L. L. (1983). Remembering the data: Analyzing interactive processes in reading. Journal of Verbal Leaming \& Verbal Behavior, 22, 485-508.

JACOBY, L. L., \& DAllas, M. (1981). On the relationship between autobiographical memory and perceptual learning. Journal of Experimental Psychology: General, 110, 306-340. 
Kolers, P. A., Roediger, H. L., III (1984). Procedures of mind. Journal of Verbal Learning \& Verbal Behavior, 23, 425-449

LoFTUs, G. R. (1985). Evaluating forgetting curves. Journal of $E x$ perimental Psychology: Leaming, Memory, \& Cognition, 11, $397-406$

MACKEN, W., \& HAMPSON, P. (1991). Integration, elaboration, and recollective experience. Manuscript submitted for publication

MANDLER, G. (1980). Recognizing: The judgment of previous occurrence. Psychological Review, 87, 252-271.

Mandler, G. (1988). Memory: Conscious and unconscious. In P. R. Solomon, G. R. Goethals, C. M. Kelley, \& B. R. Stephens (Eds.), Memory: Interdisciplinary approaches (pp. 84-106) New York: Springer-Verlag.

Mogg, K., Gardiner, J. M., Stavrou, A., \& Golombok, S (in press) Recollective experience and recognition memory for threat in clinical anxiety states. Bulletin of the Psychonomic Society.

Parkin, A. J., Reid, T. K , \& Russo, R. (1990). On the differential nature of implicit and explicit memory Memory \& Cognition, 18, 507-514.

PARKIn, A. J., \& Walter, B. (1991). Recollective experience, normal aging, and frontal dysfunction. Manuscript submitted for publication

Richardson-Klavehn, A., \& Bjork, R. A. (1988). Measures of memory. Annual Review of Psychology, 39, 475-543.

RoEdiGER, H. L., III, \& BLAxTon, T. A. (1987). Retrieval modes produce dissociations in memory for surface information. In D. Gorfein \& R. R. Hoffman (Eds.), Memory and cognitive processes: The Ebbinghaus centennial conference (pp. 349-379). Hillsdale, NJ: Erlbaum.

Roediger, H. L., III, Weldon, M. S. , Chalus, B. H. (1989). Explaining dissociations between implicit and explicit measures of retention: A processing account. In H. L. Roediger III \& F. I. M. Craik (Eds.), Varieties of memory and consciousness: Essays in honour of Endel Tulving (pp. 3-41). Hillsdale, NJ: Erlbaum.

RUBIN, D. A. (1982). On the retention function for autobiographical memory. Journal of Verbal Learning \& Verbal Behavior, 21, 21-38

SCHACTER, D. L. (1987). Implicit memory: History and current status. Journal of Experimental Psychology: Learning, Memory, \& Cognition, 13, 501-518.

SCHACTER, D. L. (in press). Perceptual representation systems and implicit memory: Toward a resolution of the multiple memory systems debate. In A. Diamond (Ed.), Development and neural bases of higher cognitive function. Annals of the New York Academy of Sciences.

Schacter, D. L., Delaney, S. M., CoOper, L. A. (1990). Implicit memory for unfamiliar objects depends on access to structural descriptions. Journal of Experimental Psychology: General, 119, 5-24.

Sherry, D. F., Schacter, D. L. (1987). The evolution of multiple memory systems. Psychological Review, 94, 439-454.

SlameCKa, N. J. (1985). On comparing rates of forgetting: Comment on Loftus (1985). Journal of Experimental Psychology: Learning. Memory, \& Cognition, 11, 812-816.

Slamecka, N. J., McElree, B. (1983). Normal forgetting of verbal lists as a function of their degree of learning. Joumal of Experimental Psychology: Learning, Memory, \& Cognition, 9, 384-397.

Sloman, S. A., Hayman, C. A. G., Ohta, N., Law, J., TUlving, E. (1988). Forgetting in primed fragment completion. Jour- nal of Experimental Psychology. Learning, Memory, \& Cognition, 14, 223-239.

SQuiRE, L. R. (1989). On the course of forgetting in very long-term memory. Journal of Experimental Psychology: Leaming, Memory, \& Cognition, 15, 241-245.

Tulving, E. (1983). Elements of episodic memory. New York: Oxford University Press.

Tulving, E. (1985a). How many memory systems are there? American Psychologist, 40, 385-398

Tulving, E. (1985b). Memory and consciousness. Canadian Psychologist, 26, 1-12.

Tulving, E , \& Schacter, D. L. (1990) Priming and human memory systems. Science, 247, 301-306

Tulving, E., Schacter, D. L., Stark, H. A. (1982). Priming effects in word-fragment completion are independent of recognition memory. Journal of Experimental Psychology: Learning, Memory, \& Cognition, 8, 336-342

UNDERWOOD, B. J. (1964). Forgettıng. Scientific American, 210(3), 91-99.

UNDERWOOD, B J. (1969). Are we overloading memory? In A. W. Melton \& E. Martin (Eds.), Coding processes in human memory. Washington, DC: Winston.

VELMANS, M. (in press). Is human information processing conscious? Behavioral \& Brain Sciences.

Wickelgren, W. A. (1972). Trace resistance and the decay of longterm memory. Journal of Mathematical Psychology, 9, 418-455.

Wiluams, J. M. G., Watts, F., Macleod, C., Mathews, A. (1988). Cognitive psychology and emotion disorders. Chichester, U.K.: Wiley.

\section{NOTES}

1. These analyses also assume that the use of an interaction test is an appropriate procedure for comparing rates of forgetting, a precedure that has been challenged by Loftus (1985), who put forward an alternative model for evaluating forgetting curves. In this matter, we are persuaded by the arguments made by Slamecka (1985; Slamecka $\&$ McElree, 1983) in favor of the more direct, less theoretically committed approach entailed by straightforward tests of interactions (for an endorsement, see Baddeley, 1990, pp. 254-255)

2. We are grateful to Douglas Nelson for drawing this point to our attention.

3 Unpublished data collected in collaboration with Vernon Gregg directly support these assertions. The data are from experiments in which subjects had to report not just "remember" and "know" judgments but, in addition, the actual mental experiences that gave rise to these judgments. "Know" responses were never accompanied by reports of recollective experiences. "Remember" responses were almost always accompanied by particular recollections from the study phase; these quite often concerned autobiographical incidents.

(Manuscript received September 24, 1990; revision accepted for publication May 13, 1991.) 